RESILIENCE IN PHYSICAL EDUCATION

Resilience in Physical Education: A qualitative exploration of protective factors.

Tudor, K. ${ }^{1}$, Sarkar, M., ${ }^{2} \&$ Spray, C. ${ }^{3}$

${ }^{1}$ Nuffield Department of Primary Care Health Sciences, University of Oxford, Radcliffe Observatory Quarter, Woodstock Road, Oxford, OX26GG.

${ }^{2}$ School of Science and Technology, Nottingham Trent University, Nottingham, NG14FQ.

${ }^{3}$ School of Sport, Exercise and Health Sciences, Loughborough University, Epinal Way, Loughborough, Leicestershire, LE113TU 


\title{
RESILIENCE IN PHYSICAL EDUCATION
}

\begin{abstract}
Resilience refers to findings that some individuals have good outcomes despite exposure to stressors, and protective factors are defined as influences that alter a person's response to such stressors. Academic resilience research identifies factors that promote positive educational outcomes; however no research to date investigates student resilience in the unique context of Physical Education (PE). The current study sought to explore protective factors that alter secondary school students' responses to the common stressors associated with PE participation. Interviews and focus groups were conducted with six teachers and 54 students, and transcripts were analysed using thematic analysis. In line with the conceptualisation of protective factors, higher order themes of individual assets and environmental factors were identified. Individual assets included personality, cognitive factors (e.g. value of PE activities) and behavioural factors (e.g. attending extra-curricular activities). Environmental factors included teacher and peer support, and the relative importance of PE promoted by the school and parents.
\end{abstract}

\section{Keywords}

Secondary school, resilience, daily hassles, everyday stressors 


\section{RESILIENCE IN PHYSICAL EDUCATION}

\section{Introduction}

Physical Education (PE) in schools provides a context for structured physical activity participation; however, evidence suggests that students do not achieve sufficient moderate-tovigorous physical activity (MVPA) to attain health benefits (Hollis et al., 2017; Lonsdale et al., 2013). Research has been conducted to identify factors relating to students' level of engagement in lessons, identifying: enjoyment or interest (Jaakkola et al., 2017), physical self-concept (Babic et al., 2014), perceived competence (Fairclough, 2003), the teaching approach (Grắstén, 2016), and self-determined motivation (Aelterman et al., 2012; Mitchell et al., 2013; Standage et al., 2005). While the identification of predominantly cognitive factors has contributed to understanding of what promotes active participation in PE, previous findings do not explain the total variance of students' active participation in lessons. One concept that has been studied within educational psychology is how students' levels of resilience in the face of stressors can predict positive educational outcomes (e.g. motivation and engagement [Martin, 2013; Martin and Marsh, 2008]). To date, there has been no research on the role of resilience on positive outcomes, for example, student motivation, engagement and psychological wellbeing in PE.

\section{What is resilience?}

The concept of resilience refers to findings that some individuals have relatively good psychological outcomes, despite exposure to acute or chronic stressors that are associated with negative outcomes (Rutter, 2006). While a number of definitions of resilience exist across a variety of disciplines, most incorporate three pivotal concepts: stressors, positive adaptation, and protective factors (Luthar, Cicchetti, and Becker, 2000; Luthar, Sawyer, and Brown, 2006; Rutter, 2006). The three concepts that comprise resilience can be applied to the PE context. We 


\section{RESILIENCE IN PHYSICAL EDUCATION}

begin by summarising each of these components, how they can be applied to the PE context, and how resilience theory could be used to explain student outcomes in PE.

\section{Stressors}

Stressors are most commonly thought of as events that impinge upon a person (Lazarus and Folkman, 1984), or as the experiential circumstances that result in a stress response (Pearlin, 1989). Lazarus and Cohen (1977) refer to three types of stressors that individuals experience, including: cataclysmic changes (affecting a large number of people), major changes (affecting one or a small number of people), and daily hassles. Cataclysmic changes may include natural disasters, or catastrophes such as war. Major changes affecting an individual (or small number of people) include, for example, the death of a loved one, divorce, or illness. Later, 'chronic strains' were identified as another type of stressor, referring to the harsh and ongoing physical or social conditions associated with disadvantage, for example, poverty or disability (Evans, 2006).

Early research into resilience focused on children's responses to significant biological and psychosocial stressors (i.e. major and cataclysmic changes, and chronic strains). More recently, research has uncovered the cumulative detrimental effects of daily or frequently occurring stressors (also known as 'hassles'), and consequently, how individuals adapt to such stressors. Psychologists have gathered evidence for the immense adaptational significance of these relatively minor, yet cumulative daily hassles (DeLongis, Coyne, Dakof, Folkman, and Lazarus, 1982; Kanner, Feldmen, Weinberger, and Ford, 1987; Kanner et al., 1981). Evidence suggested that it was the daily hassles, rather than the infrequent major life events, that had proximal significance for psychological and physiological outcomes. Specifically, the frequency and intensity of hassles over nine months explained psychological and somatic health better than 


\section{RESILIENCE IN PHYSICAL EDUCATION}

life events (Lazarus, 1984; Lazarus and Folkman, 1984). For adolescents, daily stressors can include: disagreements with peers, teachers and family, experiencing peer pressure, academic pressures, or navigating romantic relationships (Kanner, Feldmen, Weinberger, and Ford, 1987). Adolescents' experiences of daily stressors are associated with psychological maladjustment, including anxiety, depression, aggression and conduct problems (Santiago et al., 2017; Torres et al., 2012; Vaessen et al., 2017; Zeiders, 2017). Moreover, daily stressors have been found to be associated with poorer concentration and performance at school (Lundquist et al., 2000; Torres et al., 2012).

Research to date has identified some potential stressors that students experience during PE lessons. Elliott and Hoyle (2014) suggested that wearing a particular PE kit led to selfconsciousness in female students and O'Connor and Graber (2014) highlighted the increased tendency for bullying in PE, predominantly ignited by body shape and size, attire, and physical ability. Furthermore, the public and competitive nature of PE compared to other classroom-based subjects may lead to greater concern with regards to ability and performance (Yli-Piipari et al., 2009), which is supported by findings that perceived physical competence was associated with

students' experiences of apprehension at the prospect of being negatively evaluated in PE lessons (Ridgers, Fazey, and Fairclough, 2007). Researchers have also highlighted the unique context that PE places students in. PE represents one of the most significant contexts in which body image and physical self-perceptions impact on student experience (Fox and Edmunds, 2000). Indeed, PE is an environment whereby "the body is explicitly used, displayed and talked about" (Paechter, 2003 p. 49) and research has identified body image issues as a stressor relating to PE participation (Tudor, Sarkar, and Spray, 2018). 


\section{RESILIENCE IN PHYSICAL EDUCATION}

A recent qualitative investigation explored the range of stressors that many students experience in PE (Tudor et al., 2018). The study conducted focus groups with students specifically selected to reflect a range of ability, motivation and engagement in PE lessons. Participants were asked to discuss specific situations in PE that they found stressful, using the conceptualisation of daily stressors: "the irritating, frustrating, distressing demands that to some degree characterize everyday transactions with the environment” (Kanner et al., 1981, p.3).

Stressors relating to the social (e.g. negative transactions with peers and teachers, perceptions of peer effort), organizational/ physical (e.g. changing room experiences, availability of activities) and performance environment (e.g. skill acquisition, public performances) were cited by students. Stressors ranged from what one might consider as minor, such as being pressured to get changed quickly, to severe, such as experiencing bullying.

\section{Positive Adaptation}

Positive adaptation refers to "behaviourally manifested social competence" (Luthar and Cicchetti, 2000 p. 858) or the ability to meet age appropriate tasks, which is relative to the adversity examined. To illustrate, if a child is exposed to a severe life adversity (e.g. maltreatment) then near average functioning (i.e. the absence of psychological problems) would be appropriate to justify resilience (Afifi and MacMillan, 2011). If an individual experiences less severe, nonetheless demanding challenges, such as daily stressors at school, relating to performance, then excellent functioning in the relevant domain would be necessary to demonstrate the existence of positive adaptation (Davis et al., 2009). Furthermore, if a child is exposed to a serious life adversity that directly impacts the likelihood of academic success, then 


\section{RESILIENCE IN PHYSICAL EDUCATION}

average academic functioning should be considered appropriate to justify the demonstration of positive adaptation.

In the context of PE, positive adaptation may be indicated by numerous behaviours. For example, being engaged in the lesson following the experience of stressor would reflect positive adaptation. This may mean being physically engaged, by increasing physical activity, or remaining cognitively engaged by focussing on the task (Martin and Marsh, 2008).

Demonstrating persistence would indicate positive adaptation. Additionally, maintaining adequate psychological wellbeing in response to a stressor would indicate positive adaptation (Luthar and Cicchetti, 2000; Fletcher and Sarkar, 2013).

\section{Protective factors}

Protective factors are defined as “influences that modify, ameliorate, or alter a person's response to some environmental hazard" (Rutter, 1985, p. 600). Protective factors may alter one's appraisal of the environmental hassle (i.e. not perceiving it as harmful), or by modifying one's response after the stressor has been experienced. Garmezy (1993) identified three variables that operate as protective factors for adolescents at risk of poor academic outcomes including: psychological factors (e.g. perceived competence); family context (e.g. involved parenting); and external support (e.g. supportive teachers). Research conducted within an academic setting has sought to identify factors that mediate students' adaptation to everyday academic stressors, for example, receiving negative feedback (Martin and Marsh, 2008a, 2009). Martin and colleagues have identified "the 5Cs", comprising of, control (low uncertain control), composure (low anxiety), co-ordination (planning), confidence (self-efficacy), and commitment (persistence). The 5Cs have all been found to be significantly related to positive adaptation to everyday school 


\section{RESILIENCE IN PHYSICAL EDUCATION}

stressors. Specifically, students with high levels of confidence, commitment, and composure were more able to 'bounce back' from the academic stressors that they experienced. Schoolbased approaches aimed at fostering resilience to stressors (both academic and personal) promote problem-solving skills, perseverance, and a positive emotional and behavioural attitude towards hard work in the face of failure (Hart and Heaver, 2015). Interventions include targeting protective factors, such as: individual assets (e.g. problem solving, sense of purpose, selfesteem); interpersonal factors (e.g. empathy, social competence); friends and family factors (e.g. family connectedness and positive peer relationships) and community factors (e.g. school/community connectedness).

\section{Applying resilience theory to the PE context}

Existing theories of resilience tend to be specific to the population or context they are being applied to. For example, academic resilience theory applies to students' adaptation to academic stressors. Most incorporate the notion that resilience is a dynamic process that changes over time, and therefore is not a trait that an individual possesses (Luthar et al., 2000; Rutter, 2006). Within this process, there is an interaction of a wide range of protective factors, including individual differences (e.g. personality, individual beliefs) and external resources (e.g. social support), that determines whether students will demonstrate resilience. As noted, there is no such resilience theory developed for the unique context of PE. In PE lessons, students may utilise different protective factors to modify the effects of stressors. To our knowledge, no study has explored resilience to the everyday stressors associated with participation in PE lessons. The current study aims to explore the protective factors that students utilise during PE lessons that may (a) alter 


\section{RESILIENCE IN PHYSICAL EDUCATION}

their appraisal of the stressors and (b) ameliorate the effect of their response following the experience of a stressor.

\section{Methods}

Participants

Participants included 54 students $($ male $=21$; female $=33)$ aged between 11 and $16(\mathrm{M}=13.0$; $\mathrm{SD}=1.14)$, and six PE teachers (male $=$ four; female $=$ two), with a range of two to 12 years teaching experience $(\mathrm{M}=7.2, \mathrm{SD}=3.70)$. Participants were aged between 11-16. This age range was selected to explore a broad range of experiences among students from all secondary school year groups. Participants were recruited from five secondary schools located in the Midlands of England. The five schools were mixed-gender comprehensive schools. Schools ranged in socioeconomic status: four schools had a below average number of students who were eligible for free school meals, and one school had above average. All schools had a majority of White British students. Pseudonyms are used throught the text, which allows the participants' identities to remain anonymous.

\section{Design and procedure}

Ethical clearance was obtained from the ethics committee of a British university. Participants were recruited by writing to the head-teachers, explaining the study, and inviting the schools to participate in focus groups with a sample of students, and interviews with PE teachers. If the head-teacher accepted the invite and consent was granted, PE teachers were contacted by the lead researcher, explaining the details of the study. Parents of the selected students were sent letters three weeks prior to the focus groups taking place. Letters explained the objectives of the study and described the procedures in detail, including the types of questions the students would 


\section{RESILIENCE IN PHYSICAL EDUCATION}

be asked. Parents were asked to contact the first author, or their child's PE teacher within two weeks of receiving the letter if they objected to their child taking part. Additionally, at the beginning of each focus group, the researcher described what the discussion would be about, and gained students' verbal assent to participate. Semi-structured interviews were conducted with teachers and focus groups were conducted with students. All interviews were recorded using a dictaphone, and audio-recordings were subsequently transcribed by the lead author. Notes were recorded throughout the interviews and focus groups to facilitate later analysis. The decision was made to interview both teachers and students to get richer detail about the experience of stressors in PE. It was felt that teachers may provide another perspective of the experience of students in lessons that students may, or may not, discuss during focus groups. The approach to interviewing both students and teachers is an approach commonly utilised in educational research (Wellington, 2015).

\section{Students focus groups}

In total, nine focus groups were conducted. Teachers were instructed to select five or six students, ranging in physical ability and engagement in PE, to form each focus group. Each focus group consisted of students from the same class, and therefore the same age and gender. A focus group approach was chosen for a number of reasons. First, focus groups are proposed to be appropriate for situations where research aims to draw upon participants' beliefs, attitudes, and feelings by utilising group processes, such as participants building on each other's ideas (Ennis and Chen, 2012). Second, the focus group approach was chosen in an attempt to reduce the adult-child power relationship that may be a disruptive element in one-to-one interviews. 


\section{RESILIENCE IN PHYSICAL EDUCATION}

Construction of focus groups with participants of the same age and gender was designed to facilitate an environment whereby students felt comfortable (Ennis and Chen, 2012).

A focus group guide was constructed to ensure that questions were focused on the topic under study. To begin, students were asked to talk about what they thought resilience meant (e.g. "Have you heard of the word resilience?" "Does anyone know what the word resilience means?"). . Following this, the three components of resilience (i.e. stressors, positive adaptation and protective factors) were discussed in sequence. Students were asked to identify and discuss potential stressors in PE lessons (e.g. "Can you tell me about a situation in PE that you found challenging or irritating?").. Next, students were asked to think about a student who responds well (positively adapts) in the face of these stressors, and thin specifically about what a positive response would be. Finally, protective factors were explored by asking students to discuss the reasons why some people are able to respond positively to stressors in PE ("Think about a person in your class that is good at responding well when irritating or upsetting things happen in PE. What do you think the reason is that they are good at this?") The focus-group guide consisted of open-ended probe questions that aimed at initiating group discussions. The full focus group and teacher interview guides are available on request from the corresponding author. Following piloting, by testing the interview questions with a group of five students, the student focus group guide was altered to make questions more coherent for participants (specifically by altering the wording of questions). Focus groups were conducted during students' scheduled PE lessons by the first author.

Sample size could not be pre-determined, given the need for a thorough exploration of an as yet unknown phenomenon (Morse, 2003). There are various interpretations, quality assurances, and expectations with regards to the concept of data saturation in qualitative research 


\section{RESILIENCE IN PHYSICAL EDUCATION}

(O’Reilly and Parker, 2013). Due to time constraints (i.e. collecting data during scheduled PE lessons) the focus groups were limited to one hour each. Focus groups therefore ranged from 35 to 55 minutes. Despite these constraints, we felt that each focus group was conducted to a point at which all questions were explored in detail and the experiences of all participants were captured (Morse, 2003; O’Reilly and Parker, 2013). Each focus group was audio-recorded and transcribed verbatim, producing 226 pages of single-spaced transcribed text. Each focus group transcript was analysed prior to further data collection to ensure all themes were thoroughly explored.

\section{Teacher interviews}

For most of the questions, the interview guide for teachers was similar in content to the focus group guides for students; however, language was changed to meet the differences in student and teacher comprehension levels. Additional questions were added that applied to teachers specifically, for example, "Is there anything that you do during lessons to support students to be resilient following setbacks?" Before interviews began, the researcher explained the nature of the discussion and described how the data would be used. Teachers were invited to ask the researcher any questions and asked to sign a consent form if they were happy to participate. Interviews were conducted with PE teachers during their free time. In most cases, interviews were conducted individually. In one interview, two teachers were present for convenience. Interviews ranged between 16 and 29 minutes. As with the student focus groups, interviews were audio-recorded and transcribed verbatim, producing 60 pages of transcribed single-spaced text.

\section{Data analysis}




\section{RESILIENCE IN PHYSICAL EDUCATION}

A thematic analysis technique was employed through both inductive (i.e. derived from the data) and deductive (i.e. derived from the conceptual framework of the study) analysis (Braun and Clarke, 2006). The analysis followed a six-stage process: (1) familiarisation with the data through the manual transcription of interviews; (2) the generation of initial codes of salient features of the data; (3) identifying themes within the codes; (4) reviewing the themes; (5) defining the identified themes and (6) reporting the findings, extracting data that corresponds to the identified themes (Braun and Clarke, 2006; Clarke and Braun, 2013). A reflective diary, to note the researcher's initial thoughts during data collection, was utilised to guide the analysis.

The transcripts from the student focus groups and teacher interviews were analysed simultaneously, that is, each interview was analysed in the order that they took place (preceding further data analysis). Therefore, themes may have derived from the teacher data, the student data, or both. Data analysis was an iterative process between data and existing theory, that is, that resilience involves the interaction of both individual and environmental factors. However it is imperative to acknowledge the active role of the researcher in identifying themes in thematic

analysis, selecting those that are of interest to the researcher. The authors made decisions regarding the data and themes did not passively emerge from the data. Therefore the themes reported should be considered as a result of on-going interpretation and reflection (Braun and Clarke, 2006).

\section{Methodological rigor}

Methodological rigor refers to the intellectual precision, robustness, and appropriateness of methodologies (Smith and McGannon, 2018). To ensure the credibility and trustworthiness of the data, discussions took place within the research team throughout the analysis to ensure 


\section{RESILIENCE IN PHYSICAL EDUCATION}

alternative interpretations of the data were considered (Smith, 2007). The lead author coded $100 \%$ of the data. Discussion of the generated themes and the categories were reviewed and refined so the findings could be considered credible and transferable. Some doubts and disagreements arose (KT and $\mathrm{CS}$ ) with regard to coding and categorization into themes and subthemes. Consequently, having reviewed the transcripts, the second author (MS) was approached to address the disagreements. In the cases of doubt, a discussion took place between all three researchers until a majority consensus was reached (i.e. two were in agreement).

\section{Results}

The results derived from the thematic analysis procedures are a representation of participants' collated responses. Table 1 has been constructed to highlight higher order themes that showed clear links to the most frequently reported lower order themes. The interview data yielded quotes comprised of 16 first order themes and six higher order themes. In line with previous conceptualisations of protective factors (Garmezy, 1993; Rutter, 1985), the higher order themes formed two general dimensions of: individual assets and environmental resources.

\section{Individual assets}

Individual assets were comprised of second order themes of cognitive factors, personality traits, and behavioural factors.

\section{Cognitive Factors}

Value. Understanding the value of PE, or the value of a particular activity/topic in PE, facilitated students' ability to positively adapt from stressors: "Say in circuit training, I don't enjoy it 


\section{RESILIENCE IN PHYSICAL EDUCATION}

necessarily but when I do it wrong I want to know how to do it, because I know it benefits me so I keep trying to do circuit training properly" (Hannah, year 10). Thus, valuing the activity may alter the effect of the stressor (i.e. doing something wrong) and positive adaptation to the stressor (i.e. continuing to attempt the circuit). However, in other students, lacking value in a particular activity meant that their poor performance of the activity was not perceived as a stressor: "If the teacher said to me [in netball] 'You're not passing the ball properly', I don't really care because I'm never going to need to know how to pass a ball at any other time" (Hannah, year 10). In this case, 'lacking value' could be viewed as protective, since no stressors were perceived and the students' wellbeing is not affected. However, in terms of positive outcomes in PE lessons, including behavioural and cognitive engagement, having little value is not protective.

Perceived competence. Students' perceived competence facilitated their ability to positively adapt to stressors in PE. Those who were confident in their own physical abilities were described as being more able to deal with the negative effects of setbacks in PE lessons:

Some people are a bit negative, so they think, 'oh I'm terrible at this, I'm just not good at it' so they won't be determined to get better at it. They think, 'I'm terrible at this' so I'm not going to persevere (Luke, year seven).

While the role of perceived competence has been studied in the PE context (Braithwaite et al., 2011), it has not been studied within the framework of resilience, that is, a mediator between stressors/challenge and adaptation. The concept of perceived competence relates to research on students' 'implicit theories'. Implicit theories refer to an individuals' view about the malleability versus stability of their attributes (Dweck, 1999). To illustrate, a student with an 'entity theory' of their physical ability believes that their abilities are fixed, while those with an 


\section{RESILIENCE IN PHYSICAL EDUCATION}

'incremental theory' believe that skills are malleable and improved with effort and practice.

Perceptions of the malleability versus stability of skills were reported frequently by students and teachers, suggesting that students with an entity theory of physical ability were less resilient to performance stressors compared to incremental theorists. This was presented aptly by one year seven student:

Some people think about how they were at primary school and if they weren't good at something at primary school then they think, 'Oh because I wasn't good at it then then I'm never gonna be good' so they just give up instead of trying (Jenna, year seven).

Early research into implicit theories was conducted on adolescents' theories of their intelligence (Dweck, 2006; Dweck and Leggett, 1988); however research has begun to investigate implicit theories of physical ability (Ommundsen, 2001; Warburton and Spray, 2013). Thus, future research may investigate the role of implicit theories as a protective factor within the framework of resilience in PE lessons.

Commitment. Consistent with the academic resilience literature (Martin and Marsh, 2008a), participants reported commitment and dedication as a cognitive factor that ameliorated the effect of stressors on outcomes. Specifically, with regard to performance stressors, students who were committed to the self-improvement of physical skills were likely to positively adapt to the frustrations of making mistakes: "When we know we're not as good at something then we'll keep practicing at it and get better. We're more committed than some of the other girls" (Caley, year 9). It is important to note however that it was the higher ability students (as perceived by their teacher), who reported being committed to self-improvement following difficulties. This 


\section{RESILIENCE IN PHYSICAL EDUCATION}

highlights the number of interconnecting factors that influence how students adapt to the physical challenges they experience in PE.

Autonomy. Autonomy was a cognitive factor that influenced adaptation to minor stressors in PE. However, it was a lack of autonomy that facilitated adaptation to minor stressors in PE. When questioned about how they overcame specific emotions resulting from performance stressors, such as feeling embarrassed or self-conscious, students simply stated that there was no other option than to just carry on: [talking about being resilient when doing cross-country] "we weren't given a choice to drop out so you had to do it. Even if you ended up being like 40 minutes or something, you're not allowed to not try" (Gemma, year 10). Similarly, students reported working in groups with classmates who they had previously "fallen out" with, stating that they found this to be a stressor but had no other choice, so they had to "just get on with it" (Matthew, year eight).

This idea contrasts with research utilising the Self-Determination Theory (SDT; Deci and Ryan, 1985) to investigate motivation in PE lessons. Findings in this area demonstrate that low levels of autonomy (i.e. little or no choice) are related to lower participation in PE lessons (Lonsdale, Sabiston, Raedeke, Ha, and Sum, 2009; Taylor, Ntoumanis, and Standage, 2008). Therefore, while 'no choice' may result in immediate positive adaptation to minor stressors, for example by completing a fitness test, it may be that students adapt with less enthusiasm and motivation. Furthermore, it may have detrimental effects on longstanding motivation and engagement in PE and physical activity.

Personality traits. There is debate in the psychological literature as to whether resilience is a trait or a process (Jacelon, 1997; Masten, 2001). While the conceptualisation utilised in the current paper is that it is a process, it is possible that having a particular character trait may 


\section{RESILIENCE IN PHYSICAL EDUCATION}

modify students' ability to positively adapt to stressors. To illustrate, some participants stated that extraverted students were more likely to demonstrate resilience in PE lessons:

The ones who are more resilient are the ones that would just like the attention anyway. So the ones that would be like 'Oh I did rubbish on that test, never mind', because they are confident people... they're not afraid to share that and almost show off the fact they've done badly, whereas as some students are so introverted it would be the most embarrassing thing ever. (James, teacher)

More specifically, teachers felt that extraversion influenced the way in which stressors were appraised, meaning that extraverted students do not interpret certain stimuli (e.g. demonstrating physical incompetence) as harmful to their wellbeing. Participants also reported that students with "drive" showed greater resilience in PE lessons. The concept of drive has overlapping qualities of commitment and dedication, discussed above, but suggests a more innate capacity in some students, rather than a conscious process: "It's that inner drive that pulls them through" (Dave, teacher).

\section{Behavioural factors}

Participation in extra-curricular activity. Students also reported behavioural factors that reinforced positive adaptation to stressors in PE. Participating in sports clubs after school and outside of school meant that students were more accustomed to experiencing performance stressors (e.g. difficulties grasping skills) and therefore felt more able to overcome such stressors during their PE lessons: 


\section{RESILIENCE IN PHYSICAL EDUCATION}

Boxing's [club outside of school] like a tough sport, like you're always getting told bad stuff like, you gotta work on this and you gotta work on that, so like when you come here you just take it as like, a doddle really. (Alex, year eight).

Other students reported similar feelings, proposing that attending activities outside of PE lessons allowed them to experience negative feedback and constructive criticism, which they understood would develop their skills in the long-term. As with some other overlapping subthemes in this discussion, the availability of extra-curricular activities could be classed as an environmental resource that facilitates resilience (as opposed to an individual behavioural asset) given that students cannot attend extra-curricular clubs if they are not available to them.

Approaching challenge. Participants often discussed failure avoidance (i.e. actively avoiding opportunities to display one's physical abilities) as a behaviour that inhibited positive adaptation to stressors relating to performance. Older female students recalled times where they did not attempt particular activities, especially when performing in front of the opposite sex: "When we were playing rounders with the boys I just hit the ball first time and was like, 'oh, I'm out' even though I wasn't out" (Maya, year 10). Here, the stressor is performing in front of the opposite sex. Being fully engaged with the activity, that is, hitting the ball and running around the bases, would indicate positive adaptation. 'Approaching challenge' , as opposed to failure avoidance, would be a protective factor that would promote active participation in the lesson. Similarly, both male and female students described non-resilient students as those who walked the entirety of a cross country course or did not participate in fitness tests to ensure they would "come last" on their own terms. Thus, actively seeking challenge may act as a mediator between the experience of performance stressors and continued motivation and engagement. 


\section{RESILIENCE IN PHYSICAL EDUCATION}

\section{Environmental resources}

Environmental resources were comprised of three lower order themes of peers, teachers, and parental factors.

\section{Teachers}

Differentiation. All teachers recalled their own technique for ameliorating the effects of performance stressors is to provide scaled options for students, to account for differences in ability within the same group:

When we were doing table tennis, some of the lads are very able, holding their rallies.

But one pupil, David, he couldn't hit the ball back. And looking around, he's in a social setting and he's getting really frustrated and he just didn't want to do it. So what I did in the lesson was differentiated, so differentiated the equipment, so he went to a sponge ball to start and doing a co-ordination around some cones to get his confidence up. Then he went to a rally with a bigger ball and all of a sudden he experienced success. (Joe, teacher).

Thus, teachers provided greater opportunities for successful execution of a skill in response to failure to ensure that students are motivated to persevere. The concept of differentiation has not been addressed within the framework of resilience. As this theme was consistently reported as the most important facilitator of resilience in $\mathrm{PE}$, future research may consider testing the impact of differentiation in an experimental study. This is not the first study to report the positive effects of differentiation in PE lessons (Aelterman et al., 2016; Jagacinski 


\section{RESILIENCE IN PHYSICAL EDUCATION}

and Nicholls, 1984), however it is yet to be tested whether differentiating tasks can mediate the influence of stressors and positive adaptation in PE lessons.

Reinforcing resilient behaviour. Another environmental resource that was recalled in the focus groups was teachers' positive reinforcement of resilient behaviours. For example, students recalled situations whereby classmates had stepped out of their comfort zone to perform a skill or activity that they had previously failed at. Reinforcement from their teachers encouraged students to continue to approach difficult challenges:

There are some kids that are not so good at rugby, but then if they make a challenge [make a tackle] then the teacher will say "well done, keep doing that" and that encourages them to do it more. (Dom, year seven).

Moreover, some teachers suggested that the use of 'effort grades' as opposed to achievement grades in PE facilitated students' resilience, as it was a form of positive reinforcement for their continued engagement irrespective of performance or ability. This lower order theme of reinforcing resilient behaviours relates to the substantial work of social cognitive theories of achievement motivation (Ames, 1992a, 1992b; Nicholls, 1984) and motivational climate in PE lessons (Goudas and Biddle, 1994). Previous research supports the positive effects of teachers providing a 'mastery' climate, that is, providing high praise for effort regardless of actual achievement, as opposed to a 'performance climate' (i.e. praising superior ability or performance). Moreover, the importance of reinforcing resilient behaviours in PE is consistent with the TARGET framework, proposed by Ames (1992a, 1992b) and Epstein (1989). The TARGET framework is a means of understanding how PE teachers' behaviours can emphasise mastery of tasks. The 'R' of the TARGET acronym represents 'recognition' (i.e. the manner of distributing rewards such as praise), and research demonstrates that endorsing these behaviours 


\section{RESILIENCE IN PHYSICAL EDUCATION}

results in positive behavioural, affective, and cognitive outcomes in PE lessons (Braithwaite, Spray, and Warburton, 2011). Thus the facets of TARGET, for example 'recognition', may mediate the relationships between stressors and positive adaptation.

Teaching resilience early. Positive reinforcement is something that teachers agreed should be utilised as early as possible. A number of teachers proposed the importance of teaching resilience from "grass roots" and frequently emphasising to students that they need to “just keep going" when things get difficult (Dave, teacher). During the introduction to the focus groups, the researcher asked each group what they understood by the word "resilience". The majority of students could not give a response. Teaching students the concept and value of resilience is not explored in the academic resilience literature, therefore it would useful to investigate whether teaching the meaning of resilience could impact positive adaptation in lessons.

Specific feedback. Similarly, teachers providing specific feedback in response to failure facilitated students' positive adaptation to performance stressors. Providing clear and achievable direction for students promoted a student's tendency to try activities again:

Mr. S is one of those teachers that like, if you're struggling or something, he'll tell you what to do for it to be better, then you do it again, and he'll say 'no that's still not right' and tell you what to do, so then you'll keep persevering and keep trying to do better. And I've heard you get better grades with Mr. S, because they're like that. (Chris, year nine). Student-teacher relationship. Both teachers and students recalled that students who had a good relationship with their teachers were more likely to positively adapt to stressors in PE. However, a good relationship may be the 'side effect' of perceived competence, as students who described a strong bond with their PE teacher tended to be those who perceived themselves to be 


\section{RESILIENCE IN PHYSICAL EDUCATION}

already motivated in lessons. That is, students who are already competent and motivated to improve further are more likely to communicate with their teachers and seek advice.

Peers

Social status. Peer dynamics were a resource that students and teachers suggested facilitated their positive adaptation to potential stressors in PE lessons. All teachers proposed that social status modified the effects of stressors (see Table 1):

I'd say the most resilient learners are the ones that have got the social status where they don't really care about other people's opinions, because if they're already up and above in y'know the cool crew they think 'Yeah actually I've failed at this but I'll try again. I'm not affected by your opinion.' A learner who is a bit more insecure about their social status in the group might take it more to heart if they've failed. (Joe, teacher):

Peer dynamics worked in one of two ways. First, teachers suggested that students who felt secure in their social status did not appraise particular situations as stressful, where other (less secure) students would. These students were unaffected by the potential social impact of their failure and continued to persevere. Students reinforced the idea that 'popularity' protected some students from the negative impact of social stressors and performance stressors in PE (see Table 1).

Being with friends. Similarly, students who perceived themselves to be less 'popular' felt protected from the impact of stressors if they were in groups with their friends: "You've always got one friend that you're happy to work and if you do something wrong [i.e. performance stressor] you just think, oh it doesn't matter, and you keep on trying at it." (Emma, year seven). 


\section{RESILIENCE IN PHYSICAL EDUCATION}

Earlier in this discussion, we reported that understanding the value of subjects modified students' positive adaptation to stressors in PE lessons. This cognitive variable was highly influenced by the school culture and parental influence, and thus an environmental contributor. Specifically, teachers reported that when students had parents who reinforced the value of PE, they were more likely to positively adapt to setbacks in PE with the aim of developing their skills. Moreover, some students recalled their parents' views on PE as impacting their resilience to performance stressors in PE. The following quote came from a male student who self-reported as a nonresilient student in PE, tending to "give up" in response to initial failure in acquiring physical skills:

My dad just said to me when I was in year seven and year eight, just like care about the subjects that you're gunna take for GCSE, and that it doesn't really matter how you do in the other ones. (Max, year nine).

A similar theme of school culture also impacted students' responses to working at acquiring physical skills following setbacks. Many students recalled that their school prioritised core subjects, such as Maths, English and Science, over PE:

'cause with PE there's just not the same pressure as in other subjects. If you get something wrong in Maths then you might worry because you have the pressure that you might fail the exam, whereas in PE, we're not doing an exam in it... There's not that pressure to do it right -

It almost makes you more relaxed in PE... I almost look forward to PE 'cause I don't have that pressure to do well. (Hannah and Georgia, year ten). 


\section{RESILIENCE IN PHYSICAL EDUCATION}

This feeling that teachers prioritised academic subjects was repeated by many students, who suggested that PE lessons were a time to relax, with less focus on self-improvement. These environmental influences therefore may work in the opposite way to protective factors, inhibiting students' positive adaptation to performance stressors in PE.

\section{Discussion}

Recent research investigating students' positive adaptation to daily academic stressors has primarily focussed on cognitive factors, including low uncertain control, commitment and composure (Martin et al., 2010; Martin and Marsh, 2008, 2009). This study extends current research by identifying unique cognitive factors that may facilitate resilience in the PE context. Furthermore, it explored environmental factors that may ameliorate the impact of stressors on positive adaptation.

A number of the protective factors explored in the current study have conceptual overlap with existing theories of motivation, for example SDT (Deci and Ryan, 1985) and Achievement Goal Theory (Ames, 1992a). Protective factors relating to teachers creating an environment that reinforces effort is likened to research showing positive effects of creating a mastery climate in PE. Within the sport and exercise psychology literature, there has been an increased call for researchers to integrate psychological theories. In a review of the application of the SDT to sport and exercise, Hagger and Chatzisarantis (2008) suggested that future research should endeavour to combine SDT with other theories of motivation. Theoretical integration may provide an optimal explanation of behaviour and identify commonalities in motivational constructs across theories, reducing redundancy by restricting psychological predictors of outcome behaviours. This study highlights the opportunity to combine existing motivation theories within the 


\section{RESILIENCE IN PHYSICAL EDUCATION}

framework of resilience, investigating motivational constructs (e.g. motivational climate, implicit theories) as mediators of stress and positive adaptation.

\section{Practitioner implications}

The current study highlights protective factors that teachers may target to facilitate students' resilient processes in PE lessons. 'Differentiation' was the most frequently identified protective factor that ameliorates the relationship between stressors and positive adaptation. The differentiated instructional model (Tomlinson, 1999) encourages teachers to respond to the needs of all students, with specific attention given to each student's readiness, interest, and abilities. Tomlinson (1999) outlines a number of specific criteria which PE teachers may incorporate to facilitate students' positive adaptation to performance stressors in particular. For example, teachers may utilise a variety of instructional approaches aimed at modifying content (i.e. what students learn), support (i.e. how students make sense of content), and the product (i.e. how students demonstrate what they have been taught). More recent research in the field of PE highlights the benefits of graded competition (Hastie, Ward, and Brock, 2017), whereby leagues are arranged that match students of similar skill level against one another. However, previous research in PE has demonstrated that, while PE teachers recognise the value in differentiating in their lessons, they find it particularly challenging to meet the needs of all students (Whipp, 2004). Given the importance of differentiation in facilitating students' responses to performance stressors, teachers may prioritise finding ways to use empowering and inclusive techniques that might reduce students' disengagement following poor performance.

The study highlighted that the tendency to approach new challenges was a potential protective factor that promoted positive outcomes in the face of stressors. To encourage students' 


\section{RESILIENCE IN PHYSICAL EDUCATION}

tendency to embrace challenge, practitioners may utilise additions to the curriculum that create opportunities for challenge by students' own choice. For example, efforts have been made by researchers to develop a pedagogical model for Outdoor Adventure Education (OAE) to encourage controlled exposure to new challenge (Williams and Wainwright, 2016). OAE involves direct and purposeful exposure to adventurous activities with the aim to facilitate both intra- and interpersonal growth (Meyer and Wenger, 1998) and research shows this may have a positive effect on students' psychological outcomes (Sheard and Golby, 2007). Creating new opportunities for students to approach challenge may promote their tendency to utilise this protective factor.

The findings showed that teachers perceive that students who are more popular, who are more secure in their social status, and do not care about what their peers think, demonstrate the most resilience after experiencing an environmental stressor. Thus, this might encourage teachers to create environments that support students who are less secure to demonstrate resilience. Related to this, the findings highlight the effect of different kinds of student-teacher relationships on students' positive adaptation to performance stressors. The exploratory findings suggested that those students who reported a strong and positive relationship with their teachers were more likely to positively adapt to the stressors that they experience. Those who suggested that they disengaged in response to a performance stressor did not report having a bad relationship with their PE teachers, but appeared indifferent with regards to their relationship. Recent findings indicate that some students believe that their teachers focus more on high ability students in comparison to low ability students (Tudor, Sarkar, and Spray, 2018). Moreover, research has explored how the PE teaching context can influence teachers' motivational strategies towards students, suggesting that PE teachers are influenced by their perception of students' motivation 


\section{RESILIENCE IN PHYSICAL EDUCATION}

in PE. Specifically, teachers may develop stronger relationships with students who are selfdetermined and motivated in lessons (Pelletier, Séguin-Lévesque, and Legault, 2002). For example, Taylor, Ntoumanis, and Standage (2008) reported a positive relationship between PE teachers' perceptions of students' motivation and how emotionally involved and structured their teaching environments were. The current findings may encourage teachers to focus on an equal relationship with all students, regardless of their motivation and behaviour.

\section{Limitations and future directions}

The current study requested PE teachers to select students from their class who reflected a range of ability levels, motivation and engagement in PE. While this may have been achieved, there is a possibility that the sample reflected students that were more likely to respond positively to questions about their experience in PE lessons. Future research may benefit from seeking a random selection of students and complement focus group and interview data with observations of PE lessons. Moreover, the participants in the current study were mainly White British, therefore future research may benefit from exploring the views of individuals from a range of ethnic backgrounds. Furthermore, the subthemes of protective factors reported were predominantly factors that would facilitate responses to performance stressors. Previous research has shown that students experience organisational and social stressors during lessons, and more emphasis of these during the focus group may have identified more varied protective factors.

\section{Conclusion}

The current study identified and explored unique protective factors that may facilitate resilience in the PE context, specifically revealing individual assets and environmental resources that may 


\section{RESILIENCE IN PHYSICAL EDUCATION}

ameliorate the impact of stressors on positive adaptation. The findings highlight protective factors that teachers may target to facilitate students' resilience in PE lessons. 


\section{RESILIENCE IN PHYSICAL EDUCATION}

\section{Declaration of conflicting interests}

The authors declared no potential conflicts of interest with respect to the research, authorship, and/or publication of this article.

\section{Funding}

KT is funded by Oxford Biomedical Research Council.

\section{References}

Aelterman N, Vansteenkiste M, Van Keer K, et al. (2012) Student's objectively measured physical activity levels and engagement as a function of between-class and between-student differences in motivation toward physical education. Journal of Sport \& Excercise Psychology 34(4): 457-480.

Afifi TO and MacMillan HL (2011) Resilience following child maltreatment: A review of protective factors. Canadian Journal of Psychiatry 56(5): 266-272.

Ames C (1992) Achievement goals and the classroom motivational climate. In: Schunk D and Meece J (eds) Student Perceptions in the Classroom. London: Lawrence Erlbaum Associates, pp. 327-348.

Ames C (1992) Classrooms: Goals, structures, and motivation. Journal of Educational Psychology 84: 261-271.

Babic MJ, Morgan PJ, Plotnikoff RC, et al. (2014) Physical Activity and Physical Self-Concept in Youth: Systematic Review and Meta-Analysis. Sports Medicine 44(11): 1589-1601.

Braithwaite RE, Spray CM and Warburton V (2011) Motivational climate interventions in physical education: A meta-analysis. Psychology of Sport and Exercise 12(6): 628-638. Braun V and Clarke V (2006) Using thematic analysis in psychology. Qualitative Research in Pschology 3(2): 77-101. 


\section{RESILIENCE IN PHYSICAL EDUCATION}

Clarke V and Braun V (2013) Teaching thematic analysis: Overcoming challenges and developing strategies for effective learning. The Psychologist 26(2): 120-123.

Coyne J, Kanner AD and Hulley L (1979) Life events, hassles, and adaptation: A test of the shoelace hypothesis. Paper presented at Meeting of the Western Psychological Association.

Davis MC, Luecken L and Lemery-Chalfant K (2009) Resilience in common life: Introduction to the special issue. Journal of Personality 77(6): 1637-1644.

Deci EL and Ryan RM (1985) The general causality orientations scale: Self-determination in personality. Journal of Research in Personality. 19(2): 109-134.

DeLongis A, Coyne J, Dakof G, et al. (1982) Relationship of daily hassles, uplifts, and major life events to health status. Health Psychology 1(2): 119-136.

Dweck C (1999) Self-Theories: Their Role in Motivation, Personality, and Development. Philadelphia, Penn: Psychology Press.

Dweck CS and Leggett EL (1988) A social cognitive approach to motivation and personality. Psychological Review 95(2): 256-273.

Dweck S (2006) Mindset: The New Psychology of Success. New York: Random House Incorporated.

Elliott D and Hoyle K (2014) An examination of barriers to physical education for Christian and Muslim girls attending comprehensive secondary schools in the UK. European Physical Education Review 20(3): 349-366.

Ennis CD and Chen S (2012) Interviews and Focus Groups. In: Armour K and MacDonald D. $2^{\text {nd }}$ ed. Research Methods in Physical Education and Youth Sport. New York: Routledge, pp. $217-236$.

Evans GW (2006) Child development and the physical environment. Annual Review of 


\section{RESILIENCE IN PHYSICAL EDUCATION}

\section{Psychology 57: 423-451.}

Fairclough S (2003) Physical activity, perceived competence and enjoyment during high school physical education. European Journal of Physical Education 8(1): 5-18.

Fletcher D and Sarkar M (2013) Psychological Resilience: A Review and Critique of Definitions, Concepts and Theory. European Psychologist. 18: 12-23.

Fox KR and Edmunds LD (2000) Understanding the world of the" fat kid": Can schools help provide a better experience? Reclaiming Children and Youth 9(3): 177.

Garmezy N (1993) Children in poverty: resilience despite risk. Psychiatry 56: 127-136.

Grắstén A (2016) Testing the model of motivational climate, goal orientations, expectancy beliefs, task values in school physical education, and associated links to light- to vigorousintensity physical activity. International Journal of Sports Psychology 47(5): 408-427.

Hagger M and Chatzisarantis N (2008) Self-determination Theory and the psychology of exercise. International Review of Sport and Exercise Psychology 1(1): 79-103.

Hart A and Heaver B (2015) Resilience interventions: What works? Available at: http://www.boingboing.org.uk/wp-content/uploads/2017/02/angie-and-becky-school-basedresilience-approaches-dec-12.pdf (accessed 1 September 2016).

Hollis JL, Sutherland R, Williams AJ, et al. (2017) A systematic review and meta-analysis of moderate-to-vigorous physical activity levels in secondary school physical education lessons. International Journal of Behavioral Nutrition and Physical Activity 14(1): 52

Jaakkola T, Yli-Piipari S, Barkoukis V, et al. (2017) Relationships among perceived motivational climate, motivational regulations, enjoyment, and PA participation among Finnish physical education students. International Journal of Sport and Exercise Psychology 15(3): 273-290. Jacelon CS (1997) The trait and process of resilience. Journal of advanced nursing 25(1): 123- 


\section{RESILIENCE IN PHYSICAL EDUCATION}

129.

Kanner AD, Coyne JC, Schaefer C, et al. (1981) Comparison of two modes of stress measurement: Daily hassles and uplifts versus major life events. Journal of Behavioral Medicine 4(1): 1-39.

Kanner AD, Feldmen SS, Weinberger DA, et al. (1987) Uplifts, Hassles, and Adaptational Outcomes in Early Adolescents. Journal of Early Adolescence 7(4): 371-394.

Lazarus RS (1984) Puzzles in the Study of Daily Hassles. Journal of Behavioral Medicine 7(4): $375-389$.

Lazarus RS and Cohen J (1977) Environmental Stress. In: Altman I and Wohwill J (eds) Human Behaviour and Environment. Boston, MA: Springer.

Lazarus RS and Folkman S (1984) Stress, Appraisal and Coping. New York: Springer.

Lonsdale C, Sabiston CM, Raedeke TD, et al. (2009) Self-determined motivation and students' physical activity during structured physical education lessons and free choice periods. Preventive Medicine 48(1): 69-73.

Lonsdale C, Rosenkranz RR, Peralta LR, et al. (2013) A systematic review and meta-analysis of interventions designed to increase moderate-to-vigorous physical activity in school physical education lessons. Preventive Medicine 56(2): 152-161

Lundquist P, Holmberg K and Landstrom U (2000) Annoyance and effects on work from environmental noise at school. Noise and Health 2(8): 39-46.

Luthar SS, Cicchetti D and Becker B (2000) The construct of resilience: a critical evaluation and guideline for future work. Child Development 71(3): 543-562.

Luthar SS, Sawyer JA and Brown PJ (2006) Conceptual issues in studies of resilience: Past, present, and future research. Annals of the New York Academy of Sciences 1094: 105-115. 


\section{RESILIENCE IN PHYSICAL EDUCATION}

Luthar SS and Cicchetti D (2000) The construct of resilience: Implications for interventions and social policies. Development and Psychopathology 12(4): 857-885.

Martin AJ and Marsh HW (2008a) Academic buoyancy: Towards an understanding of students' everyday academic resilience. Journal of School Psychology 46(1): 53-83.

Martin AJ and Marsh HW (2008b) Workplace and academic buoyancy: Psychometric assessment and construct validity amongst school personnel and students. Journal of Psychoeducational Assessment 26(2): 168-184.

Martin AJ and Marsh HW (2009) Academic resilience and academic buoyancy: multidimensional and hierarchical conceptual framing of causes, correlates and cognate constructs. Oxford Review of Education 35(3): 353-370.

Martin AJ, Colmar SH, Davey LA, et al. (2010) Longitudinal modelling of academic buoyancy and motivation: Do the '5Cs' hold up over time? British Journal of Educational Psychology 80(3): 473-496.

Masten AS (2001) Ordinary Magic: Resilience Processes in Development. American Psychologist 56(3): 227-238.

Mitchell F, Gray S and Inchley J (2013) 'This choice thing really works ...' Changes in experiences and engagement of adolescent girls in physical education classes, during a school-based physical activity programme. Physical Education \& Sport Pedagogy 20(6): 593-611.

Morse JM (2003) A Review Committee's Guide for Evaluating Qualitative Proposals. Qualitative Health Research 13: 833-851.

O’Connor JA and Graber KC (2014) Sixth-grade Physical Education: An acculturation of bullying and fear. Research Quarterly for Exercise and Sport 85(3): 398-408. 


\section{RESILIENCE IN PHYSICAL EDUCATION}

O’Reilly M and Parker N (2013) ‘Unsatisfactory Saturation': A critical exploration of the notion of saturated sample sizes in qualitative research. Qualitative Research 13(2): 190-197.

Ommundsen Y (2001) Pupils Affective Responses in Physical Education Classes: the Association of Implicit Theories of the Nature of Ability and Achievement Goals. European Physical Education Review 7(3): 219-242.

Paechter C (2003) Power, bodies and identity: How different forms of Physical Education construct varying masculinities and femininities in secondary schools. Sex Education 3(1): 47-59.

Pearlin LI (1989) The sociological study of stress. Journal of Health and Social Behaviour $30(3): 241-256$

Ridgers ND, Fazey DMA and Fairclough SJ (2007) Perceptions of athletic competence and fear of negative evaluation during physical education. British Journal of Educational Psychology 77(2): 339-349.

Rutter M (1985) Resilience in the face of adversity. Protective factors and resistance to psychiatric disorder. The British Journal of Psychiatry 147(6): 598-611.

Rutter M (2006) Implications of resilience concepts for scientific understanding. Annals of the New York Academy of Sciences 1094: 1-12.

Santiago C, Brewer S, Fuller A, et al. (2017) Stress, coping, and mood among Latino adolescents: A daily diary study. Journal of Research on Adolescence 27(3): 556-580.

Sheard M and Golby J (2007) Hardiness and undergraduate academic study: The moderating role of commitment. Personality and Individual Differences 43(3): 579-588.

Smith B and McGannon KR (2017) Developing rigor in qualitative research: problems and opportunities within sport and exercise psychology. International Review of Sport and 


\section{RESILIENCE IN PHYSICAL EDUCATION}

Exercise Psychology 11(1): 101-121.

Smith JA (2007) Qualitative Psychology: A Practical Guide to Research Methods. London: Sage.

Spray CM and Warburton VE (2011) Temporal relations among multidimensional perceptions of competence and trichotomous achievement goals in physical education. Psychology of Sport and Exercise 12(5): 515-524.

Standage M, Duda JL and Ntoumanis N (2005) A test of self-determination theory in school physical education. British Journal of Educational Psychology 75(3): 411-433.

Torres MVT, Mena MJB, Fernandez-Baena FJ, et al. (2012) Assessment and treatment of daily stress in childhood. Evaluacion y tratamiento del estres cotidiano en la infancia. 33(1): 3035.

Tudor K, Sarkar M and Spray C (2018) Exploring common stressors in physical education: A qualitative study. European Physical Education Review.

Vaessen T, van Nierop M, Decoster J, et al. (2017) Is sensitivity to daily stress predictive of onset or persistence of psychopathology? European Psychiatry 45:167-173.

Warburton V and Spray C (2013) Antecedents of approach-avoidance achievement goal adoption: An analysis of two physical education activities. European Physical Education Review 19(2): 215-231.

Williams A and Wainwright N (2016) A new pedagogical model for adventure in the curriculum : part one - advocating for the model. 21(5): 481-500.

Yli-Piipari S, Watt A, Jaakkola T, et al. (2009) Relationships between physical education students' motivational profiles, enjoyment, state anxiety, and self-reported physical activity. Journal of Sports Science \& Medicine 8(3): 327-336.

Zeiders KH (2017) Discrimination, daily stress, sleep, and Mexican-origin adolescents' 


\section{RESILIENCE IN PHYSICAL EDUCATION}

internalizing symptoms. Cultural diversity and ethnic minority psychology 23(4): 570-575. 